\title{
O ACESSO À JUSTIÇA: REALİDADE OU FICÇÃO, NESTE INÍCIO DE SÉCULO XXI?
}

\author{
Angélica Ferreira Rosa* \\ José Sebastião de Oliveira**
}

SUMÁRIO: Introdução; 20 Acesso à Justiça; 2.1 Os Obstáculos e a Realidade do Acesso à Justiça; 2.2 Das Soluções Judiciais na Efetivação do Acesso à Justiça; 2.3 Das Soluções Extrajudiciais como Concretizadores do Acesso à Justiça; 3 Considerações Finais; Referências.

RESUMO: O acesso à justiça é considerado como um dos direitos fundamentais garantidor do acesso dos menos favorecidos à justiça. Vários são os mecanismos que podem ajudar no rompimento das barreiras que evitam o pleno acesso à justiça, tais como processos céleres, com menos despesas, emprego do procedimento simplificado, com ampla atuação dos defensores dativos, da população e do Congresso Nacional, em relação à elaboração e, nas decisões dos magistrados, ministros e desembargadores com relação à aplicação da lei, a qual tem de se adaptar às necessidades sociais, para proteger aqueles que estão em situação de vulnerabilidade.

PALAVRAS-CHAVE: Acesso à justiça; Ficção; Obstáculos; Realidade.

\section{ACCESS TO JUSTICE: REALITY OR FICTION, IN THIS BEGINNING XXI CENTURY?}

ABSTRACT: Access to justice is considered as one of the fundamental rights of access of the underprivileged to justice. There are several mechanisms that can help in breaking the barriers that prevent full access to justice, such as rapid processes, with less expense, use of the simplified procedure, with broad performance of datives defenders of the population and the National Congress, in relation to development and in the decisions of judges, ministers and judges regarding the application of the law, which must adapt to social needs, to protect those who are in vulnerable situations.

\footnotetext{
Mestre em Direitos da Personalidade pelo Programa de Mestrado em Ciências Jurídicas do Centro Universitário Cesumar (UniCesumar); Doutoranda na Universidade Federal do Paraná (UFPR); Advogada dativa da Comissão de Ética da subseção de Maringá (Pr); Docente da Faculdade Campo Real em Guarapuava (PR), Brasil. E-mails: angelicaferreirarosa@hotmail.com; prof_angelicarosa@camporeal.edu.br

** Doutor em Direito pela Pontifícia Universidade Católica de São Paulo (PUCSP) e Pós-doutor em Direito pela Universidade de Lisboa, Portugal; Docente e Coordenador no Programa de Mestrado em Ciências Jurídicas Stricto sensu do Centro Universitário Cesumar (UniCesumar); Pesquisador do Instituto Cesumar de Ciência, Tecnologia e Inovação (ICETI); Maringá (PR), Brasil.
} 
KEY WORDS: Access to justice; Fiction; Obstacles; Reality.

\section{EL ACCESO A LA JUSTICIA: ¿REALIDAD O FICCIÓN, EN ESTE COMIENZO DE SIGLO XXI?}

RESUMEN: El acceso a la justicia está considerado como uno de los derechos fundamentales que garantiza a los desfavorecidos el acceso a la justicia. Varios son los mecanismos que pueden ayudar a romper las barreras que evitan el pleno acceso a la justicia, tales como procesos más céleres, menos costosos, empleo de procedimiento simplificado, con amplia actuación de los defensores dativos, de la población y del Congreso Nacional en relación a la elaboración y, en las decisiones de los magistrados, ministros y magistrados con relación a la aplicación de la ley, la cual debe adaptarse a las necesidades sociales, para proteger a aquellos que están en situación de vulnerabilidad.

PALABRAS-CLAVE: Acceso a la justicia; Ficción; Obstáculos; Realidad.

\section{INTRODUÇÃO}

O problema do acesso à justiça é histórico para as pessoas desprovidas de recursos, desde a antiguidade a maioria das pessoas não conseguia acessá-la e tal realidade se estende no tempo, hodiernamente tem se entendido que o acesso à justiça não significa só o acesso aos tribunais, mas sim o direito às informações corretas e de ser amparado por profissionais qualificados na proteção dos direitos.

Textos como os das Ordenações Filipinas e a Constituição de 1824 orientavam para a necessidade e/ou conveniência de auto ou heterocomposição dos conflitos, para que as soluções passassem a estar fora do contexto somente jurisdicional, por isso, a relevância dos meios alternativos de conflitos.

O processo é muitas vezes lento, caro, não resolvendo o conflito, mas sim uma parte do mesmo que está sendo objeto da lide, desse modo, na maioria das vezes aqueles que se beneficiam com o processo judiciário são os que possuem dinheiro para pagar bons advogados, que podem esperar para ter o provimento jurisdicional adequado aos seus interesses, que podem pagar pelos recursos, pelas despesas do processo em si e as em detrimento do processo.

O direito ao acesso à justiça é indispensável para todos os cidadãos que não possuem condições econômicas para pleiteá-lo, o acesso da população em geral 
à justiça deve ser pleno, ou seja, não se trata de apenas colocar à disposição os instrumentos indispensáveis para que se submeta a demanda à apreciação judicial.

$\mathrm{O}$ acesso à justiça se concretiza com a simplificação de procedimentos, a diminuição de despesas processuais ou mesmo a criação de formas mais céleres de exercício dos direitos, que muitas vezes se obtêm sem nenhuma forma de intervenção judicial por meios mais simples, informais e econômicos.

O presente trabalho retrata de modo panorâmico o estudo da realidade social em conjunto com a social, para que se chegue à concretude do acesso à justiça, por isso buscou-se tratar o tema de modo detalhado a começar pela sua história, os obstáculos e as possíveis soluções, com a comprovação de que ainda que se tenha melhorado o acesso à justiça, como garantia para todos ainda é uma ficção, pois na realidade somente uma pequena parcela da população o alcança.

\section{DO ACESSO À JUSTIÇA}

O problema do acesso à justiça é histórico para as pessoas desprovidas de recursos. Desde a antiguidade havia pessoas que não conseguiam acessá-la; na Grécia, por exemplo, era comum a nomeação de dez advogados para a defesa dos pobres, perante os tribunais civis e criminais; na Idade Medieval se atribuiu à justiça eclesiástica a competência para julgar e processar as causas que envolvessem pessoas menos favorecidas.

$\mathrm{Na}$ Idade Moderna a ideia de patrocínio gratuito pelos advogados como dever honorífico ${ }^{3}$ de acesso à justiça é direito fundamental específico, o qual é assegurado no texto constitucional ${ }^{4}$; ele está configurado nesse status que foi adquirido pelo fato de ter sido reconhecido pelas constituições e pelas declarações de direitos nacionais e internacionais, em sua concretude e não como mero acesso ao poder judiciário.

Nos últimos anos tem se entendido que o acesso à justiça não significa só o acesso aos tribunais, mas que tal compreende a tutela concreta das partes, por isso deve-se assessorá-las antes, durante e após a consecução do conflito, para que não

\footnotetext{
3 Cf. FARIA, Anderson Peixoto. Acesso à justiça. Queiroz, Raphael Augusto Sofiati de. (Org). Rio de Janeiro: Lumen juris, 2002, p. 13.

${ }^{4}$ Cf. PAROSKI, Mauro Vasni. Direitos fundamentais e acesso à justiça na constituição. São Paulo: LTr, 2008, p. 137.
} 
haja simplesmente a instauração de mais um processo, afinal, a obtenção da solução jurisdicional para os conflitos de interesses muitas vezes não resolve a lide, pois "nem sempre é adequada, tempestiva e efetiva".

$\mathrm{O}$ acesso à justiça envolve a ideia de acesso aos meios estatais de solução de conflitos e dos meios extrajudiciais, ou seja, também se devem privilegiar outras formas de pacificação social e de soluções que atendam melhor o interesse dos interessados, para isto o ordenamento jurídico tem que colocar à disposição das pessoas alternativas à jurisdição que possam ser empregadas de modo voluntário, como "a arbitragem privada e a mediação".

$\mathrm{O}$ acesso à justiça é considerado garantia fundamental na maioria das sociedades modernas, mas sua efetividade depende da igualdade entre os litigantes, igualdade material é o ponto de partida ${ }^{7}$, já que na maioria das vezes um dos litigantes não se encontra em condições de igualdade em relação ao outro. Ressalta-se que o direito objetivo não deve servir jamais como escudo à realidade, o jurista não deve pouco se importar com a sociedade, somente se importando com a norma ${ }^{8}$.

$\mathrm{O}$ procedimento jurisdicional significa o rompimento de barreiras e a introdução de mecanismos de facilitação, assim, não é somente a introdução dos mecanismos, mas também o fornecimento de meios (materiais, financeiros e etc.) adequados durante todo o desenvolvimento do procedimento, "significa redução de custos, o encurtamento de distâncias, a duração razoável do processo, a diminuição de oportunidades de impugnação às decisões jurisdicionais e a efetiva participação na relação processual" .

Mauro Vasni Paroski ${ }^{10}$ acentua que o acesso à justiça talvez seja o mais básico dos direitos fundamentais, pois é por meio dele seu exercício que os outros direitos fundamentais podem ser assegurados quando violados, pela imposição de sua observância pelos órgãos estatais encarregados da jurisdição.

As primeiras constituições, na condição de cartas políticas, são o resultado da limitação dos poderes do Estado e de sua interferência ampla na vida das pessoas, como demonstrou o período da monarquia absoluta, assim, primeiro se limita a

\footnotetext{
5 PAROSKI, Mauro Vasni. op. cit., p. 138.

${ }^{6}$ Ibidem, loc. cit.

Cf. FONTAINHA, Fernando de Castro. Acesso à justiça: da contribuição de Mauro Cappelletti à realidade brasileira. Rio de Janeiro: Lumen Juris, 2009, p. 38.

${ }^{8}$ Ibidem, p. 83.

9 PAROSKI, Mauro Vasni, op. cit., p. 138.

${ }^{10}$ Ibidem, loc. cit.
} 
liberdade do Estado e depois com a falência do Estado liberal se prolifera o propósito de realização dos objetivos gerais que são o resultado da união de princípios e valores em prol de beneficiar todas as pessoas.

Os princípios portam os valores, mas não quaisquer e sim os que são eleitos pelo constituinte como importantes e fundamentais, pois o objetivo dos mesmos é a consecução de uma sociedade mais livre e igualitária, assim, eles estruturam e fundamentam todo o ordenamento jurídico na orientação dos governantes, do legislador e dos particulares ${ }^{11}$.

O Estado reserva para si o monopólio da justiça e proíbe a realização da justiça pelas próprias mãos, por isso, implica na realização da implantação dos meios alternativos de solução de conflitos de interesse, o qual deverá ser assegurado pela Constituição por intermédio da criação de instrumentos processuais eficazes e com o objetivo de atingir a paz social.

A partir da segunda metade do século XIX houve a disputa entre burguesia e proletariado, as ideias de Marx influenciaram muito nessa época, principalmente na seara trabalhista; por meio delas muitos países começaram a discutir sobre o acesso à justiça, o Capitalismo trouxe a exploração dos trabalhadores e empobrecimento de muitos em detrimento do acúmulo de riquezas de poucos.

O Direito do Trabalho emergiu como principal interessado à efetivação do acesso à justiça, afinal, ele busca a tutela integral do trabalhador que é parte mais fraca na relação jurídica, por isso, se observou que no âmbito das relações de trabalho houve a facilitação ao acesso à justiça pelo uso da conciliação e da mediação, também pela informalidade e simplicidade, a atuação do trabalhador em juízo sofreu alteração relevante com a inversão do ônus da prova e pela tutela dos interesses coletivos dos trabalhadores.

Aconsolidação doEstado contemporâneo levou a se estabelecer a necessidade da intervenção do Estado para que fossem assegurados os direitos, o modelo da não intervenção preconizado pelo Estado liberal se demonstrou insuficiente, por isso, a intervenção estatal é indispensável para a garantia da igualdade formal e material, a qual torna concreto o acesso à justiça dos menos favorecidos ${ }^{12}$.

Com o advento do Direito do Trabalho no Estado Contemporâneo passa a ser predominante o emprego de conceitos jurídicos indeterminados, com isso, atribui-se maior responsabilidade aos juízes na interpretação e aplicação do Direito.

\footnotetext{
${ }^{11}$ PAROSKI, Mauro Vasni, op. cit., p. 141.

${ }^{12}$ Ibidem, p. 164.
} 
Desse modo, o acesso à justiça que antes era tratado como uma concepção do monopólio estatal, hodiernamente cedeu espaço às novas ideias e propostas que se aderiram à crescente desjudicialização dos conflitos ${ }^{13}$.

\subsection{OS OBSTÁCULOS E A REALIDADE DO ACESSO À JUSTIÇA}

Infelizmente há muitos "obstáculos de ordem material e processual, dificultando que no Brasil seja concretizado o acesso à justiça de forma satisfatória" ${ }^{14}$. O art. $5^{\circ}$, inciso XXXV, da Constituição da República Federativa do Brasil de 1988, dispõe que o controle jurisdicional da ameaça ou lesão de direitos garante o acesso à justiça, a doutrina aduz que ele é uma garantia no ordenamento jurídico, na qual o Estado assegura de modo igualitário para todas as pessoas os meios capazes de gerarem decisões que levem à solução justa dos conflitos de interesses, tanto individuais quanto coletivos ${ }^{15}$.

$\mathrm{O}$ art. $5^{\circ} \mathrm{da} C F / 88$ propõe que não apenas o acesso ao Judiciário como também o acesso à ordem jurídica justa devem ocorrer de forma efetiva, tempestiva e adequada, não tratando de modo massificado os recursos repetitivos, não compactando os procedimentos, para dar azo a cognições parciais e sumárias, em detrimento da desejável jurisdição integral e não colocando óbices e barreiras de acesso aos Tribunais Superiores ${ }^{16}$.

Há barreiras que estão sendo positivadas sem uma indagação mais profunda quanto à legitimidade, à eficiência, à consistência técnico-jurídica das inserções de cunho restritivo, sem se preocupar com as questões que são a base do problema, como exemplo, a irrefreada formação de uma cultura demandista ou judiciária ao interno da coletividade, difundindo a percepção de que todo interesse não satisfeito e/ou contrariado tem de ser repassado à justiça estatal ${ }^{17}$.

Pode-se afirmar nas palavras de Rodolfo de Camargo Mancuso que as condicionantes legítimas e ilegítimas são barreiras ao alcance do acesso que se dá com a necessidade de aumentar a produção de sentenças mantendo sempre, pelo menos inicialmente, as mesmas portas do atual acesso, ou seja, um bloqueio ao acesso à justiça em relação às decisões ${ }^{18}$.

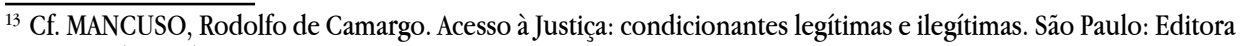
Revista dos Tribunais, 2011, p. 23.

${ }^{14}$ PAROSKI, Mauro Vasni, op. cit., p. 141.

${ }^{15}$ Ibidem, loc. cit.

${ }^{16}$ Cf. MANCUSO, Rodolfo de Camargo, op. cit., p. 26.

${ }^{17}$ Ibidem, p. 27.

${ }^{18}$ Ibidem, p. 28. 
O acesso à justiça deve atender aos anseios sociais e políticos, ainda que não exclusivamente jurídicos, para atingir a solução que abranja os valores contemplados pela ordem constitucional, ordem material e processual, as quais se encontram interrelacionadas para a concretização da ordem jurisdicional justa ${ }^{19}$.

O Estado não esgota sua função ao realizar a jurisdição mediante um processo, onde se deve assegurar a igualdade e garantir a tutela adequada a cada caso concreto, a igualdade assegurada pelo Estado deve ser real e não formal. O processo deve ser justo e imparcial, para que as todas as pessoas usufruam de igualdade de oportunidades, de modo que seja diretamente proporcional o regime democrático com o exercício da cidadania ${ }^{20}$.

Em relação à barreira do acesso à justiça por intermédio da política é entendimento que não se pode tentar resolver déficits estruturais e organizacionais por intermédio da frenética produção de normas, ao invés de ir à verdadeira fonte do problema e, com isto, descobrir programas e estratégias capazes de resolver ou pelo menos equacionar a presente crise que impede o acesso à justiçą ${ }^{21}$.

Tanto os tribunais quanto os órgãos jurisdicionados de primeiro grau são compostos por julgadores que ainda se expressam com certo conservadorismo, onde a grande maioria "aplica de modo autônomo a norma jurídica em uma forma mecânica de atuação, sem interpretação apropriada e sem valoração das circunstâncias específicas do conflito, renunciando a uma leitura das normas jurídicas por intermédio da constituição"22.

O juiz da atualidade deve ser aquele que realiza os valores democráticos para de fato concretizar o acesso à justiça, o rigorismo gerado pelo apego legal não se adequa às necessidades sociais. A liberdade individual é direito constitucional garantido pela Constituição, mas deve ser efetivada pelo judiciário sempre que o mesmo intervir.

O problema do acesso à justiça não está na "entrada", afinal, pode-se entrar na justiça por advogados pagos, não pagos, assessoria jurídica, ou até sem auxílio algum, sob tal prisma o acesso é amplo, todos de certa forma podem participar, mas o problema se concentra em relação à "saída", já que poucos saem satisfeitos durante e após o processo, a saída não tem sido racional e humana, por isso a doutrina tem que atuar no sentido de melhorar essas condições.

\footnotetext{
${ }^{19}$ Cf. PAROSKI, Mauro Vasni, op. cit., p. 142.

${ }^{20}$ Ibidem, p. 164.

${ }^{21}$ Cf. MANCUSO, Rodolfo de Camargo, op. cit., p. 29.

${ }^{22}$ PAROSKI, Mauro Vasni, op. cit., p. 165.
} 
Tanto as questões quantitativas quanto as qualitativas são barreiras ao acesso à justiça, assim como o são a força obrigatória da norma legal no interno da sociedade, o que leva ao seu recorrente descumprimento e a formação de lides judiciais, o clima geral de insegurança jurídica, a precária divulgação de outros modos e meios de resolução de pendências, a falsa percepção que a resposta jurisdicional é uma prestação primária do $\operatorname{Estado}^{23}$.

Para concretizar o acesso à justiça há que se superar a dificuldade de aceitação social da justiça nas decisões legislativas de elaboração do direito objetivo, a falta de efetividade das normas jurídicas, a falta de eficiência dos instrumentos processuais para se preservar ou reestabelecer o direito lesado, o baixo índice de confiabilidade nas instituições públicas e nos seus integrantes ${ }^{24}$.

O sentimento de impotência da população diante da impunidade no país, em relação às sanções estabelecidas para as condutas dos responsáveis pelos delitos, a ideação que a justiça está distante da população, principalmente pelo fato da magistratura ainda apresentar perfil conservador.

Os tribunais, os magistrados e a jurisprudência possuem certa responsabilidade pela quantidade expressiva de sentenças e acórdãos, os quais nem sempre estão coerentes com a Constituição ${ }^{25}$, não apenas os aplicadores da lei, mas até a doutrina tem dificuldade em fazer leituras atualizadas do direito que possam produzir modificações profundas e necessárias em sua interpretação e aplicação ${ }^{26}$.

A falta de informação também dificulta o acesso à justiça, já que sem a devida informação as pessoas não a procuram, o que não deixa de ser considerado fator de exclusão social, que pode ser considerada como o maior fator de limitação ao acesso à justiça, afinal, para a maioria da população, há insuficiência de condições econômicas ao devido custeio das despesas do processo jurisdicional ${ }^{27}$.

$\mathrm{Na}$ maioria dos Estados da federação os cartórios judiciais e extrajudiciais foram passados de pai para filho, os quais são explorados em caráter privado pela delegação do poder público. Evidenciando despesas mais comuns, como as das diligências a serem praticadas pelos oficiais de justiça, os emolumentos com práticas de atos processuais específicos, as despesas com publicação de editais em jornais, as indenizações das despesas realizadas pelas testemunhas, as diárias de viagens e

\footnotetext{
${ }^{23}$ Cf. MANCUSO, Rodolfo de Camargo, op. cit., p. 32.

${ }^{24}$ Cf. PAROSKI, Mauro Vasni, op. cit., p. 215.

${ }^{25}$ Ibidem, p. 218.

${ }^{26}$ Ibidem, loc. cit.

${ }^{27}$ Ibidem, p. 219.
} 
remuneração do assistente técnico, os honorários advocatícios e as despesas com a realização de exames.

No Brasil, os meios de redução dos óbices econômicos como a utilização da assistência judiciária, defensoria pública e assistência jurídica gratuita pelos organismos públicos, a $\mathrm{OAB}$ e pelos organismos privados são insuficientes, pois os mais pobres não constam de fato com o amparo da assistência devida pelos profissionais que com mais experiência jurídica.

Mesmo quando há concessão dos benefícios da assistência judiciária, também existem aquelas despesas relativas aos atos processuais inadiáveis, não praticados por órgãos públicos, mas por particulares que não querem ou não podem arcar com os custos das diligências sem a garantia que irão receber por esses serviços ${ }^{28}$.

O processo não atende de modo integral a função social, política e jurídica, os custos são altos e há o grande lapso temporal de duração processual, esta realidade afasta o processo da justiça, por consequência a esperança das pessoas no Poder Judiciário, também as "chicanas" processuais, as quais retardam e podem impedir o alcance da finalidade processual.

O Estado não é o único a dar soluções aos conflitos, pelos vários obstáculos que isso significa, por isso, os meios privados de composição dos conflitos de interesses, com ênfase nos que são relativos aos interesses exclusivamente individuais, como a mediação e a arbitragem, mesmo que certos conflitos só possam ser resolvidos pelos meios judiciais.

Somente ocorre o pleno acesso à justiça quando o processo é célere e eficaz, isto não significa que o magistrado deve julgar de modo técnico, sem a busca do justo, somente cumprindo metas, o que contraria a democracia, pois nela a lei vale ou não vale, no todo ou em parte, por tanto, a lei só vale no sentido que lhe é dado, desde que esteja conforme a Constituição, ou seja, a decisão não pode ser técnica e o judiciário não pode julgar conforme o pamprincipiologismo (valores escondidos debaixo da Constituição) ${ }^{29}$.

O pamprincipiologismo afasta o acesso à justiça, no Estado Democrático de Direito, o magistrado goza de autonomia, mas somente deverá deixar de aplicar a lei quando ela for inconstitucional, quando for o caso de aplicação dos critérios de resolução de antinomias, quando aplicar a interpretação conforme a Constituição,

\footnotetext{
${ }^{28}$ PAROSKI, Mauro Vasni, op. cit., p. 238.

${ }^{29}$ Cf. STRECK, Lênio. Compreender direito desvelando as obviedades do discurso jurídico. 2. ed. São Paulo: Revistas dos Tribunais, 2013, v. 1, p. 114.
} 
quando aplicar a nulidade parcial sem a redução de texto, quando for o caso de declaração de inconstitucionalidade com a redução de texto e quando for o caso de deixar de aplicar uma regra em face de um princípio ${ }^{30}$.

Deve-se observar que o Poder Judiciário vem transformando sua atuação, o marco se deu com a Constituição de 1988; a partir desse momento duas expressões passaram a ter vinculação direta à jurisdição, ativismo judicial e judicialização política $^{31}$. A judicialização é uma questão social, fenômeno este que independe da vontade do órgão judicante e em fatores externos possui ponto de amplitude em relação ao maior e mais amplo reconhecimento de direitos ${ }^{32}$.

O ativismo judicial é decorrência da ampliação da atuação do Supremo Tribunal Federal, por meio da vinculação entre Direito e Política, que é resultado do controle de constitucionalidade, como sinônimo de maior interferência do Poder Judiciário, pelo ativismo o Poder Judiciário passa a exercer políticas de governo, em que o alargamento da noção do acesso à justiça como direito constitucional é compreendido como eficiência judicial, o que tornou o judiciário uma instituição capaz de resolver todos os problemas da sociedade ${ }^{33}$.

A atuação dos tribunais por intermédio das súmulas vinculantes demonstra que o julgamento continua sendo técnico, com maior relevo que a lei, pois não há controle difuso de constitucionalidade para que se possam corrigir os erros contidos nos enunciados responsáveis por sua promulgação, afinal, as súmulas podem conter inconstitucionalidades ${ }^{34}$.

Outra barreira ao acesso à justiça pode ser observada pela redução do número de recursos pendentes no Supremo Tribunal Federal, após ter se introduzido a exigência de repercussão geral da questão constitucional ${ }^{35}$. O que contraria $o$ fato que o processo existe em função do jurisdicionado, não se tratando de uma coisificação, porém em cada processo existem pessoas físicas e jurídicas.

A pessoa física e jurídica tem direitos fundamentais, dentre eles aquele que assegura o de se dirigir ao Estado-juiz e ele de protegê-los, elaborando e implementando políticas judiciárias eficientes, o dever do Estado é prestar, segundo

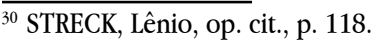

${ }^{31}$ Cf. TASSINARI, Clarissa, op. cit., p. 27.

${ }^{32}$ Ibidem, p. 32.

${ }^{33}$ Ibidem, p. 49.

${ }^{34}$ Cf. STRECK, Lênio Luiz; ABBOUD, Georges. O que é isto - o procedente judicial e as súmulas vinculantes? Porto Alegre: Editora Livraria do Advogado, 2013, v. 3, p. 108.

${ }^{35}$ Cf. TASSINARI, Clarissa, op. cit., p. 38.
} 
o art. $5^{\circ}$, o acesso à justiça (inc. XXXV), o devido processo legal (inc. LV) e também a prestação jurisdicional em tempo razoável (inc. LXXVIII).

Observa-se que o número de processos é elevado e certas decisões são de competência de outros órgãos, isto é devido ao resultado da repercussão política ou social, mas ao invés disso são proferidas decisões pelo poder judiciário, as quais deveriam ser de competência do Congresso Nacional e do poder executivo ${ }^{36}$.

Para resolver mais essa barreira em relação às súmulas cabe ao Poder Judiciário fazer um levantamento geral delas, em princípio pelas do STF e do STJ, para suprimir as que se encontram defasadas ou superadas, alterar o enunciado das parcialmente aproveitáveis e proceder a uma republicação do acervo mais atualizado, com a devida renumeração dos enunciados ${ }^{37}$.

A judicialização da política é entrave ao acesso à justiça, ocorre por meio da recusa ou oferta insatisfatória de prestações primárias, as quais deveriam ser disponibilizadas pelo poder público para todos ${ }^{38}$. Ressalvando que a separação de poderes não é óbice para se esvaziar a função jurisdicional de controle da Administração Pública ${ }^{39}$.

As causas que envolvem pequeno vulto de dinheiro são as mais prejudicadas, com o valor alto de custos, assim, pode não compensar todas as despesas, os riscos, os danos físicos e emocionais, como exemplo, estresse, insônia, irritabilidade, dentre outros.

O tempo que o processo dura é outra barreira para o acesso à justiça: quanto mais se delonga no tempo maior serão os custos e as frustrações desencadeadas, ressalvando que não há nenhuma garantia de algum tipo de retorno no resultado da lide.

Muitas vezes as barreiras de acesso à justiça são suportadas pela grande parcela da população, em detrimento daquelas pessoas e instituições que podem pagar todas as despesas e que também suportam o prazo para a resolução da lide, com a capacidade de poder contratar melhores advogados e pagar toda produção de provas, não importando o preço que tais podem perquirir.

A capacidade jurídica pessoal é expressão cunhada na obra Acesso à Justiça, de Mauro Cappelletti e Bryant Garth, que corresponde às vantagens de recursos

\footnotetext{
${ }^{36}$ BARROSO, Luís Roberto. Judicialização, ativismo judicial e legitimidade democrática. Disponível em: <http:// www.plataformademocratica.org/Publicacoes/12685_Cached.pdf>. Acesso em: 10 out. 2014.

${ }^{37}$ Cf. MANCUSO, Rodolfo de Camargo, op. cit., p. 73.

${ }^{38}$ Ibidem, p. 76.

${ }^{39}$ Ibidem, p. 82.
} 
financeiros e diferenças de educação, meio e status social, onde as classes menos favorecidas nutrem desconfiança nos advogados, nos procedimentos, os quais são complicados, pois impera o formalismo, o uso de ambientes, assim como operadores, que intimidam, como os tribunais, advogados, serventuários, com ênfase nos magistrados que são figuras tidas como opressoras, que fazem o litigante se sentir perdido ${ }^{40}$.

A busca da efetivação do acesso à justiça faz com que o estudo referente às barreiras seja pormenorizado, que os obstáculos não podem ser eliminados individualmente, afinal, alguns se autorrelacionam, por isso, se adentrará nas possíveis soluções para o acesso à justiça para que ele esteja diretamente relacionado à realidade social.

\subsection{DAS SOLUÇÕES JUDICIAIS NA EFETIVAÇÃO DO ACESSO À JUSTIÇA}

Para ser efetivo o acesso à justiça, a Constituição e o ordenamento jurídico infraconstitucional necessitam oferecer meios complementares, os quais são postos à disposição da população, inclusive quando o ato jurídico é fruto do próprio Estado, como o mandado de segurança (individual e coletivo - CF, art. $5^{\circ}$, incisos LXIX e LXX), o mandado de injunção (CF, art. $5^{\circ}$, inciso LXXI), o babeas data (CF, art. $5^{\circ}$, inciso LXXII), a ação popular (CF, art. $5^{\circ}$, inciso LXXIII), a ação direta de inconstitucionalidade (CF, art. 102, inciso I, alínea a), as ações civis públicas (CF, art. 129, inciso III) e as ações cíveis de menor complexidade afeta aos juizados especiais (CF, art. 98, inciso I $)^{41}$.

Para o "efetivo acesso à justiça há uma série de garantias associadas ao devido processo constitucional, como o contraditório, a ampla defesa, a motivação das decisões judiciais e o juiz natural (CF, art. 50, incisos XXXVII e LX, e art. 93, inciso IX)"42.

Quando a Constituição da República de 1988 regula de forma ampla o direito de ação, o qual está presente no art. $5^{\circ}$, inc. XXXV, que assevera que qualquer cidadão brasileiro ou residente no país "poderá deduzir pretensão, tendo por escopo apreciação de lesão ou ameaça a direito" ${ }^{\prime \prime}$, com a devida ressalva que a garantia

\footnotetext{
${ }^{40}$ Cf. CAPPELLETTI, Mauro; GARTH, Bryant. op. cit., p. 24.

${ }^{41}$ Ibidem, p. 144.

${ }^{42}$ MANCUSO, Rodolfo de Camargo, op. cit., p. 41.

43 PAROSKI, Mauro Vasni, op. cit., p. 183.
} 
constitucional à tutela jurisdicional preventiva ou reparatória abrange também os direitos coletivos e difusos.

A prestação jurisdicional tem índole substitutiva, ou seja, ela depende da provocação da parte ou interessado, ressalvando a observância do seu limite, pois a resposta não pode ser extra, ultra ou citra-petita, já que atua nos limites da legitimidade do magistrado ${ }^{44}$.

A legislação processual sofre reformas pontuais constantes para que haja a melhora do acesso à justiça e a efetividade processual, não basta apenas que a Constituição assegure o acesso aos órgãos judiciários, também é essencial que os meios de obtenção da tutela jurisdicional sejam adequados, céleres, econômicos e efetivos, ou que a população se utilize dos meios alternativos de solução de conflitos, os quais proporcionam estes atributos.

$\mathrm{O}$ acesso à justiça não é somente a possibilidade de ingresso em juízo ou ao processo, além da própria realização do direito material ${ }^{45}$, tendo em vista que o acesso da população em geral à justiça deve ser pleno, ou seja, não se trata de apenas colocar à sua disposição os instrumentos indispensáveis para que se submeta a demanda à apreciação do Poder Judiciário.

As leis são meios de acesso à justiça, quando necessária se faz a tutela pelo Poder Judiciário, por isso pode-se inferir que importantes textos legais foram aprovados para que houvesse o aperfeiçoamento do sistema processual e da garantia de acesso à justiça, para que as necessidades atuais advindas dos preceitos constitucionais fossem alcançadas.

A solução normativista é imediatista, ou seja, não requer providências preparatórias, o enfrentamento do problema através da etiologia substancial envolve riscos e custos políticos, ressalvando que o detentor do mandato popular se orienta pelo intento de agradar o seu próprio eleitorado, a pronta emissão e divulgação do texto preordenado a regular a crise que passa a população dando a impressão que foram tomadas todas as providências, mas que não acompanha o raciocínio acerca da eficiência da resposta ${ }^{46}$.

Os primeiros esforços importantes na busca do acesso à justiça se deram nos países ocidentais pela prestação dos serviços jurídicos aos pobres ${ }^{47}$. Na Alemanha

\footnotetext{
${ }^{44}$ Cf. MANCUSO, Rodolfo de Camargo, op. cit., p. 462.

${ }^{45}$ Cf. PAROSKI, Mauro Vasni, op. cit., p. 184.

${ }^{46}$ Cf. MANCUSO, Rodolfo de Camargo, op. cit., p. 65.

${ }^{47}$ Cf. CAPPELLETI, Mauro; GARTH, Bryant, op. cit., p. 32.
} 
começou por volta de 1919/1923 o início do sistema de remuneração dos advogados pelo Estado para o fornecimento da assistência jurídica para todos.

Depois da implementação do sistema de prestação de serviços jurídico aos pobres foram necessárias reformas, tais se desenvolveram de princípio nos Estados Unidos da América, na década de 60 , pois houve a conscientização da eminente contradição entre o ideal teórico do acesso efetivo e os sistemas inadequados da assistência judiciária.

A maior realização das reformas ocorreu na Áustria, Inglaterra, Holanda, França e Alemanha Ocidental graças ao sistema judicare; nele a assistência é considerada um direito para todos aqueles que estão na mesma situação jurídica, por meio da prestação de serviços de advogados pagos pelo Estado ${ }^{48}$.

Para a assistência judiciária ser mecanismo de rompimento das barreiras que evitam o acesso à justiça na realidade social, o sistema deverá ser eficiente, ou seja, possuir um grande número de advogados, os quais precisam receber uma boa remuneração para que seja atrativo dar assistência à população.

O problema da representação dos interesses difusos, os quais são coletivos, também apresentam barreiras ao acesso à justiça, assim houve reformas e reflexões sobre noções tradicionais básicas do processo civil, já que antes o mesmo era um assunto entre duas partes.

A assistência jurídica integral e gratuita é dever que o Estado tem que cumprir, ela está imposta no art. $5^{\circ}$, inciso LXXIV, da CF, ou seja, trata-se de um direito que é concedido para todos aqueles que não possuam condições para arcar com as despesas do processo judicial.

A defensoria pública é o resultado do dever de assistência que o Estado tem que prestar, ela está garantida pelo emprego do art. $5^{\circ}$, inc. LXXIV, da CF, asseverase que nos Estados que a defensoria pública apresenta números insuficientes de defensores, a estrutura física é deficitária e déficit de dotações orçamentárias.

$\mathrm{O}$ acesso à justiça é uma questão de consecução dos direitos humanos no plano internacional, a criação de um sistema de proteção aos direitos humanos como resposta dada aos resultados evasivos provocados após as duas grandes Guerras Mundiais ocorridas no séc. $\mathrm{XX}^{49}$, onde a capacidade jurídica internacional do indivíduo é grande conquista humanitária.

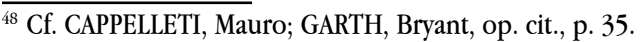

${ }^{49}$ Cf. JÚNIOR, Jayme Benvenuto Lima. Dimensões do acesso à justiça. José Mário Wanderley Gomes Neto (Coord.). Salvador: juspodivm, 2008, p. 118.
} 
A jurisprudência tem evoluído no sentido de oferecer tratamento isonômico aos jurisdicionados, assim, ela tem atuado como um filtro para possível contenção da judicialidade excessiva, pois desestimula a propositura de demandas que veiculem teses desautorizadas pela jurisprudência dominante ou sumulada, na atuação aceleratória do processo, por isso é nítido o caráter de sumarização dos ritos por meio da utilização da jurisprudência ${ }^{50}$.

$\mathrm{O}$ acesso à justiça é condição fundamental de eficiência e validade de um sistema jurídico que vise a garantir direitos ${ }^{51}$; o Estado deve prestá-lo, mas a realidade demonstra que ele só poderá ser concretizado quando todos os tipos de mecanismos auxiliadores da lei forem aplicados harmonicamente, um auxiliando o outro, em prol da valorização do indivíduo como ser humano.

\subsection{DAS SOLUÇÕES EXTRAJUDICIAIS COMO CONCRETIZADORAS DO ACESSO À JUSTIÇA}

Ao longo da história tem se observado a existência da utilização pelo homem dos meios alternativos de conflitos de interesses, tais como a autotutela, autocomposição (mediação e conciliação) e heterocomposição (arbitragem). Na arbitragem o sujeito escolhia um terceiro de confiança dele para apresentar soluções ao conflito ${ }^{52}$, antes ela era facultativa, mas com o Direito Romano passou a ser obrigatória, ou seja, ela é anterior à jurisdição pública.

A origem do processo está na arbitragem obrigatória, ela foi forma primitiva de justiça, onde os juízes nada mais foram do que árbitros, contexto que se insere na justiça privada, pois as partes que buscavam a solução do conflito pelo terceiro, período em que os sacerdotes possuíam o monopólio do conhecimento jurídico.

A Lei 9.307/96 regulou a arbitragem e instituiu o fim do estabelecimento à submissão ao crivo da homologação do Poder Judiciário do laudo arbitral, assim, como a adoção da força cogente da cláusula compromissória, o que contribui para que o procedimento seja célere, ágil e eficaz ${ }^{53}$.

A convenção arbitral apresenta os dois modos pelos quais a arbitragem pode ser constituída, por cláusula compromissória e o compromisso arbitral, ressalvando

\footnotetext{
${ }^{50}$ Cf. MANCUSO, Rodolfo de Camargo, op. cit., p. 464.

${ }^{51}$ Cf. MATTOS, Pagani Fernando. Acesso à justiça: um princípio em busca de efetivação. Curitiba: Juruá, 2009, p. 70.

${ }^{52}$ Cf. RUIZ, Ivan Aparecido; GAZOLA, Marcelo Dal Pont. Alguns aspectos primordiais da arbitragem e do acesso à justiça. Revista Jurídica Cesumar - Mestrado, v. 10, n. 1, jan./jun. 2010, p. 173.

${ }^{53}$ Ibidem, p. 181.
} 
que só com a devida previsão contratual ela poderá ser constituída. Com a celebração da cláusula compromissória as partes transferem à futura e eventual necessidade de uso da jurisdição do âmbito estatal para o privado ${ }^{54}$. A lei expressamente equipara o árbitro ao juiz de direito para os fins da arbitragem, o único requisito para desempenhar tal função é a capacidade civil, ressalvando que como o procedimento arbitral pode ser de direito ou de equidade não há necessidade que o arbitro tenha formação jurídica.

A conciliação surge como outro meio alternativo de conflito que visa ao pleno acesso à justiça, nela o terceiro neutro, imparcial, chamado conciliador auxilia as partes podendo participar em todas as áreas de atuação judiciária ${ }^{55}$. A conciliação significa entendimento, recomposição de relações desarmônicas, o acordo é apenas consequência material, por isso o magistrado deve se empenhar em esclarecer as partes do conflito, eliminar algum mal entendido e aclarar o direito da outra parte, de modo que ambos entendam seus direitos e suas obrigações, com cautela, técnica e equilíbrio ${ }^{56}$.

Com o avanço da sociedade o Estado foi se fortalecendo e passou a gerir os conflitos de interesses das pessoas, como meio de sujeitar a decisão das partes aos terceiros houve a criação do legislador, onde os juízes estatais resolvem os conflitos por meio do processo, atividade que se denomina como jurisdicional, a distinção entre o compromisso e a cláusula se estabelece pelo fato do primeiro ser referente ao conflito atual, enquanto a cláusula os eventuais e futuros ${ }^{57}$.

A conciliação é instituto antigo do direito processual civil que é diferente da mediação, pois o terceiro sempre será o juiz estatal, onde a tentativa de conciliação será sempre endoprocessual, bastante utilizada pelos Juizados Especiais, há mediação no PROCON, Defensoria Pública, Ministério Público, mas o mediador não pode sugerir um acordo como ocorre com a conciliaçãa ${ }^{58}$, os institutos operam para a consecução do pleno acesso à justiça. Recentemente a Lei 13140/2015 aduz da possibilidade de ocorrer propostas de acordo por meio do mediador e trouxe de maneira ampla as matérias que poderão ser objeto da técnica.

\footnotetext{
${ }^{54}$ RUIZ, Ivan Aparecido; GAZOLA, Marcelo Dal Pont, op. cit., p. 182.

${ }^{55}$ CF. RUIZ, Ivan Aparecido; GONÇALVES, Heloísa Alva Cortez. Da conciliação: uma forma de efetivar a jurisdição, pela via consensual, por meio de um processo mais justo. Revista Unicesumar - Mestrado, v. 11, n. 1, jan./ jun. 2011, p. 55.

${ }^{56}$ Ibidem, p. 56.

${ }^{57}$ Cf. RUIZ, Ivan Aparecido; GAZOLA, Marcelo Dal Pont, op. cit., p. 183.

${ }^{58}$ CF. RUIZ, Ivan Aparecido; GONÇALVES, Heloísa Alva Cortez, op. cit., p. 64.
} 
O Estado está em crise, fato que pode ser comprovado pela deficiência das políticas públicas, tais como habitação, saúde e educação ${ }^{59}$. Em que pese seja garantida a assistência jurídica por força do art. $5^{\circ}$, inciso LXXIV, CF/1988, a qual é gratuita e integral a todos os cidadãos, o governo pode tentar solucionar o problema do acesso com a criação de agências públicas regulamentadoras que serão altamente especializadas na garantia dos direitos públicos e interesses difusos ${ }^{60}$.

A Lei 4.215/63 regulamentou o Estatuto da Ordem dos Advogados do Brasil, assim atribui como dever profissional do advogado a assistência, ela foi inserida como dever prestacional para com os necessitados. Por intermédio das mudanças ocorridas que a assistência passa de judiciária, por não abranger exclusivamente os atos processuais, para jurídica que é aquela proporcionada pelo Estado ${ }^{61}$, a qual será proporcionada de modo integral e gratuito, por isso não se trata somente do acesso à justiça, mas também da assessoria extrajudicial - antes, durante e após o processo $^{62}$.

A defensoria pública é outro mecanismo capaz de trazer o acesso à justiça como realidade, tal foi instituída pela Constituição de 1988, no art. 134, na prestação e orientação jurídica dos necessitados, e em 12/01/1994, por força constitucional, surgiu no ordenamento jurídico a Lei Complementar 80 , que a organizou nos territórios e na União.

A defensoria é órgão criado, financiado e subsidiado pelo Estado para prestar assistência jurídica completa, afinal, ela deve ser integral, de modo a prestar aconselhamento jurídico, informação jurídica e atuação extrajudicial, com caráter assistencial. Diferentemente do que ocorre com a assistência jurídica, na defensoria os profissionais são particulares e subsidiados pelo Estado.

Os Núcleos de Assistência Jurídica das Faculdades de Direito possibilitam que as pessoas carentes de recursos possam ter acesso efetivo à realidade jurídica, pois eles em suas determinadas áreas de atuação trabalham com o atendimento de pessoas hipossufucientes.

A mediação é considerada meio efetivo de acesso à justiça, afinal, soluciona os problemas psicológicos e emocionais que poderiam levar os indivíduos a não pensar somente nas necessidades primordiais, com o uso desta técnica as partes

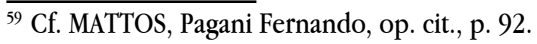

${ }^{60}$ Cf. CAPPELLETTI, Mauro; GARTH, Bryant, op. cit., p. 52.

${ }^{61}$ Cf. MATTOS, Pagani Fernando, op. cit., p. 94.

${ }^{62}$ Ibidem, loc. cit.
} 
conscientemente buscam seus direitos e deveres por meio da ajuda de um terceiro isento para com ele construir uma relação pacífica e menos litigiosa ${ }^{63}$.

A criação dos juizados especiais é uma forma de dirimir as barreiras daqueles que se encontram em situação de vulnerabilidade social, como maneira de enfrentar as causas relativamente pequenas, onde os custos e a duração processual são reduzidos, mas não basta permitir que a parte comparecesse sem advogado, afinal, isto pode prejudicá-la, já que a mesma não está apta em fazer a sua defesa técnica.

$O$ defensor dativo se faz necessário, mas a acessibilidade das pessoas comuns é marco fundamental, já que o procedimento é simplificado, assim, há evidente diminuição de barreiras ao acesso à justiça.

O duplo grau de jurisdição pode ser considerado como acesso à justiça, desde que o julgamento passe pelo reexame necessário, não apenas seja solucionado por meio de questões políticas ou não apreciado o processo no seu todo, trata-se de decisões meramente técnicas, e/ou iguais para casos diferentes, não resolve o problema do acesso à justiça.

A elaboração de planos ou convênios jurídicos pode auxiliar no alcance ao acesso à justiça, já que são mecanismos através dos quais os indivíduos concorrem com uma contribuição social na obtenção de alguns serviços jurídicos, o que dependerá do quantum da contribuição e do tipo de assessoramento, para distribuir o risco entre os que pagam a mensalidade e escolhendo os advogados tanto na prevenção quanto na solução dos casos ${ }^{64}$.

Em suma, os procedimentos modernos não podem, de modo algum, se utilizarem da suposta eficiência para abandonar as garantias fundamentais da Constituição e do Novo Código de Processo Civil, que positivou a constitucionalização do processo por meio dos princípios e garantias fundamentais, mesmo que seja importante e necessária a inovação, pois é essencial evitar arbitrariedades e injustiças, a inserção do procedimento formal por mais dispendioso oferece segurança às partes, mas ele deve ser moldado com base na concretização do acesso à justiça em conjunto com a realidade social e a acessibilidade a todos.

\section{CONSIDERAÇÕES FINAIS}

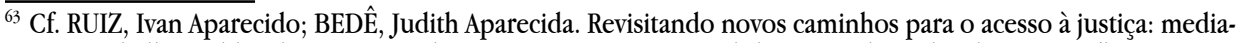
ção. Trabalho publicado nos Anais do XVII Congresso Nacional do Conpedi, realizado em Brasília (DF) nos dias 20, 21 e 22 de novembro de 2008. p. 144.

${ }^{64}$ CAPPELLETTI, Mauro; GARTH, Bryant, op. cit., p. 147. 
O processo deve estar relacionado ao tipo de litígio que eles apresentam em si suas próprias características e se diferem em complexibilidade, assim, em relação ao montante da controvérsia, algumas causas por sua natureza exigem solução rápida, então há a necessidade da aplicação apropriada, onde a relação entre as partes também serão levadas em conta, por isso, a mediação ou outros mecanismos alternativos aos conflitos são métodos mais apropriados na resolução do litígio (preserva os relacionamentos).

Há que se proteger os interesses difusos e individuais para a concretização do acesso à justiça, para isto, deve o processo ser eficiente em seus procedimentos, o que aduz a um menor formalismo e um tempo mínimo de tramitação, a utilização de alguns mecanismos como as "class action", também aparecem como possibilidade de diminuir as barreiras ao acesso à justiça.

A sociedade e os membros do Congresso Nacional devem atuar em conjunto em prol da consecução e aprovação de leis, as quais atuarão para a efetivação do acesso à justiça, com a atuação em conjunto do Poder Judiciário, o qual deve dar seguimento e cumprimento às diretrizes legais e é indispensável o emprego dos mecanismos alternativos como exigências legais em determinadas causas, como nas ações que envolvem os conflitos familiares, afinal, o processo não é capaz de solucionar os problemas psíquicos e emocionais das partes.

Deve-se utilizar da oralidade, da livre apreciação da prova, da concentração do procedimento e do contato imediato entre os juízes, às partes e testemunhas, para tentar colocar as partes em "pé de igualdade" e tornar o processo mais simples, rápido, barato e acessivel para todos, por isso, os métodos alternativos, tais como: conciliação, mediação e arbitragem são necessários, mas não com a única finalidade de diminuir o abarrotamento do Poder Judiciário.

Por todo o elencado, compreende-se que o sistema jurídico brasileiro tem criado mecanismos para o acesso à justiça de todos, mas ainda está no começo, pois não são todos que efetivamente conseguem acessar a justiça, assim, o processo em si não significa acesso à justiça, mesmo que com o Novo Código de Processo Civil houve a positivação da constitucionalização de valores e princípios fundamentais, mas ainda é indispensável o procedimento de assessoramento, consulta, informação, acompanhamentos e todas as prestações jurisdicionais cabíveis, para que o mesmo ocorra na realidade e não seja apenas fiç̧ão.

As mudanças processuais e legislativas para serem eficazes precisam estar 
em consonância com o pensamento jurisdicional, com dos operadores do Direito, para que se altere de fato a cultura que a "entrada" do processo no mundo jurídico resolverá o conflito, ou a lide, pois é inegável que o judiciário não consegue resolvêlos.

A instituição de uma nova política pública de resolução de conflitos, com ênfase na consecução dos meios heterocompositivos é que será capaz de alterar a cultura jurídica refletindo em toda a sociedade e incidindo também no ensino jurídico, com a formação de profissionais desarraigados do contencioso e atuando em prol da orientação, prevenção e composição dos conflitos que ocasionará o real acesso à justiça.

\section{REFERÊNCIAS}

BARROSO, Luís Roberto. Judicialização, ativismo judicial e legitimidade democrática. Disponível em: <http://www.plataformademocratica.org/Publicacoes/12685_ Cached.pdf > . Acesso em: 10 jan. 2015.

CARNEIRO, Daniel Carneiro. A mediação de conflitos como instrumento de acesso à justiça e incentivo à cidadania. Jus Navigandi, Teresina, ano 15, n. 2673, out. 2010. Disponível em: < http://jus.com.br/artigos/17698> . Acesso em: 12 nov. 2014.

CINTRA, Antonio Carlos de Araújo; GRINOVER, Ada Pellegrini; DINAMARCO, Cândido Rangel. Teoria geral do processo. 25. ed. São Paulo: Malheiros, 2009.

DINAMARCO, Cândido Rangel. A instrumentalidade do processo. São Paulo: Malheiros, 2005.

FIGUEIRA JUNIOR, Joel Dias. Arbitragem, jurisdição e execução: análise crítica da Lei 9.307, de 23.09.1996. São Paulo: Revista dos Tribunais, 1999.

FONTAINHA, Fernando de Castro. Acesso à justiça: da contribuição de Mauro Cappelletti à realidade brasileira. Rio de Janeiro: Lumen Juris, 2009.

LIMA JÚNIOR, Jayme Benvenuto. Dimensões do acesso à justiça. Salvador: Juspodivm, 2008. 
MANCUSO, Rodolfo de Camargo. Acesso à justiça: condicionantes legítimas e ilegítimas. São Paulo: Editora Revista dos Tribunais, 2011.

MATTOS, Pagani Fernando. Acesso à justiça: um princípio em busca de efetivação. Curitiba: Juruá, 2009.

MARINONI, Luiz Guilherme. Efetividade do processo e tutela de urgência. Porto Alegre: Sérgio Antonio Fabris, 1994.

MELLO, Celso Antonio Bandeira de. Conteúdo jurídico do princípio de igualdade. 4. ed. São Paulo: Editora Malheiros, 2005.

MORAES, Alexandre de. Direito constitucional. São Paulo: Atlas, 2007.

NETO, José Mário Wanderley Gomes (Coord.). Dimensões do acesso à justiça. Salvador: Juspodivm, 2008.

PAROSKI, Mauro Vasni. Direitos fundamentais e o acesso à justiça na constituição. São Paulo: LTr, 2008.

QUEIROZ, Raphael Augusto Sofiati de. (Org.). Acesso à justiça. Rio de Janeiro: Lumen juris, 2002.

RUIZ, Ivan Aparecido; GAZOLA, Marcelo Dal Pont. Alguns aspectos primordiais da arbitragem e do acesso à justiça. Revista Jurídica Cesumar - Mestrado, v. 10, n. 1, jan./jun. 2010.

RUIZ, Ivan Aparecido; GONÇALVES, Heloísa Alva Cortez. Da conciliação: uma forma de efetivar a jurisdição, pela via consensual, por meio de um processo mais justo. Revista Jurídica Cesumar - Mestrado, v. 11, n. 1, jan./jun. 2011.

RUIZ, Ivan Aparecido; BEDÊ, Judith Aparecida. Revisitando novos caminhos para o acesso à justiça: mediação. In: CONGRESSO NACIONAL DO CONPEDI, 17., 2008, Brasília. Anais... Brasília, DF: Conpedi, 2008.

SIQUEIRA, Dirceu Pereira; OLIVEIRA, Flávio Luis de. (Org.). Acesso à justiça e concretização de direitos. Birigui: Boreal, 2014. 
STRECK, Lênio Luiz. Compreender direito desvelando as obviedades do discurso jurídico. 2. ed. São Paulo: Revistas dos Tribunais, 2013. v. 1.

STRECK, Lênio Luiz. Hermenêutica Jurídica e(m) crise. 10. ed. Porto Alegre: Livraria do Advogado, 2011.

STRECK, Lênio Luiz. O que é isto: decido conforme minha consciência?. 2. ed. Porto Alegre: Livraria do Advogado, 2010.

STRECK, Lênio Luiz. Jurisdição Constitucional e Hermenêutica. 2. ed. Porto Alegre: Livraria do Advogado, 2004.

STRECK, Lênio Luiz; ABBOUD, Georges. O que é isto: o procedente judicial e as súmulas vinculantes?. Porto Alegre: Livraria do Advogado. v. 3, 2013.

TASSINARI, Clarissa. Jurisdição e ativismo jurisdicial: limites da atuação do Judiciário. Porto Alegre: Livraria do Advogado, 2012.

Recebido em: 27 de julbo de 2016 Aceito em: 11 de agosto de 2016 